\title{
El derecho de autodeterminación según el Derecho internacional y la reivindicación de Cataluña
}

\author{
The right to self-determination in International Law \\ and Catalonia's claim
}

Eugenia LóPEZ-JaCOISTE DÍAZ

Profesora Titular de Derecho Internacional y Relaciones Internacionales

Universidad de Navarra

ejacoiste@unav.es

\begin{abstract}
Resumen: Este trabajo analiza el alcance del derecho a la libre determinación de los pueblos, según el Derecho internacional, así como su aplicación ante situaciones más allá del contexto colonial tal y como se ha aceptado en la práctica internacional. La cláusula de salvaguarda del párrafo 7 de la Resolución 2625 (1970) sigue teniendo plena vigencia. En consecuencia, resulta inviable su lícita invocación por parte de Cataluña
\end{abstract}

Palabras clave: autodeterminación, secesión unilateral, cláusula de salvaguarda, Cataluña

\begin{abstract}
This paper analyzes the scope of the right to self-determination of peoples according to international law, as well as its application beyond the colonial context as it has been accepted in international practice. The safeguard clause of paragraph 7 of Resolution 2625 (1970) remains fully valid. Therefore Catalonia cannot validly claim such a right to self-determination.
\end{abstract}

Keywords: self-determination, unilateral secession, safeguard clause, Catalonia

Sumario: 1. INTRODUCCIÓN. 2. SIGNIFICADO Y ALCANCE DEL DERECHO A LA LIBRE DETERMINACIÓN DE LOS PUEBLOS. 3. MARCO JURÍDICO DEL DERECHO A LA LIBRE DETERMINACIÓN DE LOS PUEBLOS. 3.1. Significado del concepto de «pueblo». 3.2. El derecho de los pueblos a una secesión no colonial unilateral. 4. SOBRE LA SECESIÓN UNILATERAL DE UN PUEBLO NO-COLONIAL COMO MEDIDA DE ÚLTIMO RECURSO. 5. REFLEXIÓN FINAL: ¿ES POSIBLE LA REIVINDICACIÓN DE INDEPENDENCIA DE CATALUÑA DE ACUERDO CON EL DERECHO INTERNACIONAL SOBRE LA AUTODETERMINACIÓN?

\section{INTRODUCCIÓN}

E 1 derecho a la libre determinación de los pueblos constituye una de las normas del derecho internacional contemporáneo ampliamente aceptada como tal, pero controvertida en su aplicación. El alcance y el propósito del principio de autodeterminación han evolucionado significativamente en el siglo XX. En las primeras décadas de 1900, fue cuajando el principio de autodeterminación en la comunidad internacional al fundamentarse dicho principio en el derecho de todas las personas a su libertad indivi- 
dual y colectiva. Esta idea inspiró con éxito a los movimientos secesionistas durante la Primera y Segunda Guerra Mundial, y asentó después las bases de la futura gran descolonización en la década de 1960. De hecho, solo después de la Primera Guerra Mundial, cuando el antiguo sistema europeo comenzó a desintegrarse, el principio de autodeterminación adquirió una defensa política, influenciada por los postulados democráticos-liberales, pero también por el socialismo marxista, a través de figuras internacionales tan ideológicamente diversas como Vladimir Lenin y el presidente Woodrow Wilson ${ }^{1}$. Ambos consideraron que «pueblos» $\mathrm{y}$ «naciones» poseían este derecho, pero no especificaron el significado ni alcance de estos términos. A pesar del objetivo de consagrar el principio de autodeterminación dentro del Pacto de la Sociedad de Naciones, las dificultades prácticas para su efectividad impidieron su inclusión en el texto final de aquel documento. La autodeterminación solo fue reconocida indirectamente como aplicable a aquellos territorios sometidos a la administración extranjera, pero bajo el mandato de la Sociedad de Naciones y a aquellas otras colonias que seguían siéndolo después de la Primera Guerra Mundial. En el fondo, el Pacto de la Sociedad de Naciones estableció una fuerte desigualdad entre los pueblos, tal y como se recogía en su Artículo 22, al contemplar que los sistemas de mandatarios se «aplicarían a las colonias y territorios que, a raíz de la guerra, han cesado de hallarse bajo la soberanía de los Estados que los gobernaban anteriormente y que son habitados por pueblos aun incapaces de regirse por sí mismos». Es más, se estimaba que tal misión era un deber de los Estados y que constituía una misión sagrada de civilización, razón por la cual el Pacto debía establecer las necearías garantías para su cumplimiento. En el fondo, el citado art. 22 del Pacto legitimaba y regulaba el sistema colonial.

La cuestión de la autodeterminación de los pueblos coloniales se recoge igualmente en la Carta de las Naciones Unidas, a pesar de las conocidas posiciones políticas enfrentadas entre las grandes potencias reunidas en la Conferencia de San Francisco en 1945. La evolución interna de esta Organización y de la misma sociedad internacional van a hacer que dicho principio ya no se vea como algo programático o deseable, sino que la autodeterminación de

1 Cfr. Schaefer, R., Warpaths: The Politics of Partition, Noonday Press 1991, pp. 46-59. Sobre una hipotética, pero muy improbable «asociación» entre Lenin y Wilson, para quienes la autodeterminación y la secesión significaban lo mismo, cfr. Holsti, K., Peace and War: Armed Conflicts and International Order 1648-1989, Cambridge Studies in International Law, 1991, pp. 181-89. 
los pueblos se convertirá con el tiempo en un principio estructural del orden intencional. La injusticia del sistema colonial llevaría a la Asamblea General de las Naciones Unidas a adoptar una serie resoluciones que cambiarían la perspectiva de su aplicación. En efecto, la práctica por ejemplo en el caso de la Comisión de Arbitraje de la Conferencia para la paz en Yugoslavia $^{2}$ o el asunto de Timor Oriental ${ }^{3}$, manifiesta la opinio iuris internacional de que es un una norma de ius cogens, tal y como se contempla en el artículo 53 del Convenio de Viena sobre el derecho de los Tratados de 1969.

El concepto de autodeterminación (Self-determination) denota el derecho (inherente) de un pueblo a decidir su propio destino en el orden internacional. Es un principio básico del derecho internacional, que surge del derecho internacional consuetudinario, pero igualmente reconocido como un principio general del Derecho y está consagrado en varios tratados, declaraciones y resoluciones internacionales. Sin embargo, la ONU ha estado muy lejos de tener claro si el derecho a la libre determinación debería extenderse más allá del contexto colonial y usarse como base para permitir la secesión de grupos minoritarios oprimidos dentro de un Estado independiente. La aplicación del principio de autodeterminación en el contexto colonial ha sido la opción más habitual frente al supuesto derecho de secesión, ya que hasta finales de la década de los 60 del siglo pasado se había aceptado comúnmente que el derecho a la autodeterminación se aplicaba exclusivamente a las colonias que, en efecto, ejercieron sus derechos hasta llegar a convertirse en nuevos miembros de las Naciones Unidas.

En la práctica internacional, el principio de autodeterminación ha sido reconocido como algo que significa que todos los pueblos tienen el derecho de determinar libremente sus propias circunstancias sociopolíticas y económicas. Así se refleja en numerosos documentos de la ONU, como por ejemplo, el Artículo 1.2 de la Carta de las Naciones Unidas; la Declaración Universal de los Derechos Humanos, la denominada Declaración sobre la concesión de la independencia a los paises y pueblos coloniales recogida en la Resolución 1514 (XV), de 14 de diciembre de 1960 (en adelante Resolución 1514) ${ }^{4}$, y los dos pactos internacionales de derechos humanos de 1966, como son el Pacto Internacional de Derechos Civiles y Políticos (PIDCP) y el Pacto Internacional de Derechos Económicos, Sociales y Culturales (PIDESC). En concreto, el artí-

2 Cfr. C.P.I.J opinión consultiva de 8 de diciembre de 1927 sobre la competencia de la Comisión Europea del Danubio, reproducida, en Revue générale de droit international public, 1992, p. 265

3 C.I.J. Recueil, 1995 , p. 102.

4 AG/ R/ 1514 (XV), UN Doc. A/4684 (1961). 
culo 1 del PIDCP reafirma el derecho de «todos los pueblos... y afirma que en virtud de ese derecho determinan libremente su condición política y persiguen libremente su desarrollo económico, social y cultural». Este derecho también está consagrado en la Definición de agresión y en la Declaración sobre los principios de derecho internacional relativos a las relaciones amistosas y la cooperación entre los Estados de conformidad con la Carta de las Naciones Unidas, recogida en la Resolución 2625 (XXV) de la Asamblea General (en adelante Resolución 2625).

El preámbulo de la Resolución 1514 enfatizaba que la negativa u obstrucción de la libertad colectiva provoca la intensificación de los conflictos, por lo que en su art. 2 establece que «Todos los pueblos tienen derecho a la libre determinación; en virtud de ese derecho, determinan libremente su condición política y persiguen libremente su desarrollo económico, social y cultural». Además, insiste en que «la insuficiencia de la preparación política, económica, social o educativa nunca debe servir como pretexto para retrasar la independencia» (art. 3). En el momento de su aprobación hubo tantas opiniones divergentes sobre su contenido y alcance, como países que lo invocaron ${ }^{5}$. Para 1970, muchos nuevos Estados habían alcanzado el reconocimiento internacional como consecuencia del gran proceso de descolonización al amparo de la citada Resolución. De hecho, la Corte Internacional de Justicia confirmó la existencia del derecho a la libre determinación de los pueblos como norma del derecho internacional positivo con ocasión de su opinión consultiva sobre Namibia, en 1971. Con palabras lo suficientemente claras la Corte disipó cualquier atisbo de duda sobre el carácter sustantivo del derecho a la libre determinación de los pueblos aplicable principalmente en el contexto de la descolonización ${ }^{6}$.

Más allá del contexto colonial, el contenido y el alcance del principio resultaba más controvertido, aún si cabe ${ }^{7}$, aunque se ha llegado a invocar por diversos grupos minoritarios separatistas con el objetivo de desafiar la integridad territorial de un Estado, incluso con disturbios violentos más

5 Cfr. KaIKobaD, K., «Self-Determination, Territorial Disputes and International Law: An Analysis of UN and State Practice», Geopolitics and International Boundaries, 1996, p. 15.

6 I.C.J. Reports 1971, sobre las consecuencias jurídicas para los Estados de la presencia continuada de Sudáfrica en Namibia, a pesar de la Resolución 276 (1970) del Consejo de Seguridad, párrafo 52 .

7 Cfr. Bassiouni, S., «Self-Determination» and the Palestinians», Proceeding of the American Society of International Law, 1971, p. 31; y DinsteIN, Y., «Collective Human Rights of peoples and Minorities», International and Comparative Law Quarterly, vol. 25, 1976, p. 102. 
allá del foro estrictamente doméstico, como fue el caso de Bangladesh ${ }^{8}$, Biafra $^{9}$ y Katanga ${ }^{10}$. El esfuerzo por alcanzar la deseada autodeterminación se extendió más allá de las situaciones del Medio Oriente ${ }^{11}$ y Sudáfrica ${ }^{12}$, siempre tan volátiles, hasta provocar en tiempos más recientes grupos insurgente y separatistas en Timor Oriental ${ }^{13}$, Eritrea ${ }^{14}$, Formosa ${ }^{15}$, Kurdis-

8 Cfr., entre otros International Commission of Jurist, «East Pakistan Staff Study», International Commission of Jurist Review, 1972, p. 42; NANDA, V.P., Self-Determination in International Law: The Tragic Tale of Two Cities-Islamabad (West Pakistan) and Dacca (East Pakistan), American fournal of International Law, vol. 66, 1972, p. 321.

9 Cfr., por ejemplo, ForsyTh, F., The Biafra story, The Making of an African Legend, London, Penguin, 1969, pp. 155, 210-212; IJALAYE, D., «Was 'Biafra' at Any Time a State in International Law?», American fournal of International Law, vol. 66, 1971, pp. 551-559; NIXON, Ch. R., «Self-Determination: The Nigeria/Biafra Case», Word Politics vol. 34, 1972, p. 473; PosT, K. W. «Is There a Case for Biafra?, International Affairs, vol. 44, 1968, p. 26.

10 Cfr. Miller, L., World Order and Local Disorder: the United Nations and internal conflicts, 1967, pp. 66-117; AUMA-Osolo, A., «A Retrospective Analysis of United Nations Activity in the Congo and its Significance for Contemporary Africa», vol. 8 Vanderbilt Fournal of Transnational Law 1975, p. 451; LEMARCHAND, R., «The Limits of Self-Determination: The Case of the Katanga Secession», American Political Science Review, vol. 56, 1962, p. 409.

11 Véase, en general, O'NeILl, B., Armed Struggle in Palestine: a Political-Military Analysis, Westview/ Dawson, 1978; GEORG, N., «Self-Determination in International Law: The Palestinians», Case Western Reserve fournal of International Law, vol. 12, 1980, p. 137; CAMPBELL, J.C., «The Middle East: The Burdens of Empire», Foreign Affairs, vol. 57, 1978, p. 613; LENCZOWSKI, G., «The Arc of Crisis: Its Central Sector», Foreign Affairs, vol. 58, 1979, p. 796; PERLMUTTER, A., «A Race Against Time: The Egyptian Israeli Negotiations over the Future of Palestine», Foreign Affairs, vol. 58, 1979, p. 937; QUANDT, W. B., «The Middle East Crises», Foreign Affairs, vol. 58,1980 , p. 540.

12 Véase en general, Carter, G. M., Which Way is South Africa Going?, New York, Monad Press 1980; Gann, L.; Duignan, P., South Africa: War, Revolution or Peace? Hoover Int. 1978; JohnSON, D. L., «Sanctions and South Africa», Harvard International Law Fournal, vol. 19, 1978, p. 887.

13 Por ejmplo, Cantarow, E., «The Secret War in East Timor», Mother Fones, May 1979, p. 64; SuTER, K., West Iran, East Timor and Indonesia, Minority Rights Group Rep. No. 42, London, Sept. 1979. El 11 de noviembre de 1980, la Asamblea General de las Naciones Unidas adoptó la Resolución 35/27 reafirmando el «derecho inalienable del pueblo de Timor Oriental a la libre determinación y la independencia», y declarando que «el pueblo de ese Territorio debe poder determinar libremente su propio futuro en el marco de las Naciones Unidas».

14 Cfr. Sherman, R., Eritrea: the Unfinished Revolution, New York, Praeger, 1980; Koenn, P., «Ethiopian Politics: Military Intervention and Prospects for Further Change», Africa Today, 1975, p. 7; MARTIN, D., «War in Eritrea», New Statesman vol. 89, 1975, pp. 166, 166-167; MoRGAN, E., «A Geographic Evaluation of the Ethiopia-Eritrea Conflict», Fournal of Modern African Studies, vol. 15, 1977, p. 667.

15 Véase, por ejemplo, CHIU, H., China and The Taiwan Issue, New York, Praeger, 1979; CHEN, L.; Lasswell, H., Formosa, China and The United Nations: Formosa in the World Community 1967; Chen, L.; ReIsman, M., «Who Owns Taiwan: A Search for International Title», Yale Law fournal, vol. 81, 1972, p. 599. 
tán ${ }^{16}$, Irlanda del Norte ${ }^{17}$, Quebec ${ }^{18}$, Sudán del Sur ${ }^{19}$, el Tíbet ${ }^{20}$ y el Sahara Occidental $^{21}$.

Mientras algún sector doctrinal continúa debatiendo el significado de «auto» $\mathrm{y}$ «determinación» ${ }^{22}$, en la práctica interesa sobre todo aclarar quién puede invocarlo, así como sus problemas jurídicos concretos, cuando lo que está en juego es la secesión de Estados. Como al profesor de la Universidad de Nueva York, Thomas Franck, le gustaba decir el derecho internacional no regula las declaraciones unilaterales de independencia, pero tampoco las prohíbe $^{23}$. No existe un tratado multilateral sobre este tema, pero la lectura e interpretación de todas las fuentes de derecho internacional sugieren la existencia de un derecho limitado a una secesión correctiva o más conocido por su expresión en inglés, remedial secession.

16 Cfr., en general, EDmonds, C. E., «Kurdish Nationalism», Fournal of Contemporary History, vol. 6, 1971, p. 87; HAZEN, W. E., «Minorities in Revolt: The Kurds of Iran, Iraq, Syria, and Turkey», en The Political Role of Minority Groups in The Middle East, R. McLaurin ed. 1979, pp. 49-75.

17 Sobre su problemática, en general, cfr. O’Brien, C., States of Ireland, 1972; John Hume, «The Irish Question: a British Problem», Foreign Affairs, vol. 58, 1980, p. 300.

18 Véase Legendre, C., French Canada in Crisis: a New Society in the Making? Minority Rights Group Rep. No. 44, London, May 1980; Rene Levesque, «For an Independent Quebec», Foreign Affairs, vol. 54, 1976, pp. 734-744; MoRTON, L., «Quebec in Revolt», Canadian Forum, 1977, p. 13; SMITH, D., «Preparing for Independence», Canadian Forum, 1977, pp. 4-5; THIBODEAU, M. A., «The Legality of an Independent Quebec: Canadian Constitutional Law and Self-Determination in International Law», Boston College International \& Comparative Law Review, vol. 99, 1979, p. 179.

19 Por ejemplo, O'Ballance, E., The Secret War in the Sudan: 1955-1972, London, Faber\& Faber 1977; GRAY, R., The Southern Sudan, Fournal of Contemporary History (1971), pp. 108-20; AI-RAHIM, A., «Arabism, Africanism, and Self-Identification in the Sudan», Fournal of Modern African Studies, vol. 8, 1970, p. 233.

20 Véase, por ejemplo, SinHA, A., «How Chinese was China’s Tibet Region?», Tibetan Review, 1968, p. 7; NORBU, D., «The 1959 Tibetan Rebellion: An Interpretation», China Quarterly, vol. 77, 1979, p. 74; WALT VAN PRAAG, M., «Tibet and the Right to Self-Determination», Wayne Law Review, vol. 26, 1979, p. 279.

21 Cfr., por ejemplo, Hodges, T., «Western Sahara: U.S. Arms and the Desert War», Africa Report, vol. 25, 1980, p. 42; SolarZ, S. J., «Arms for Morocco?», Foreign Affairs, 1980, p. 278. El 11 de noviembre de 1980, la Asamblea General de las Naciones Unidas adoptó la Resolución 35/19 reafirmando «el derecho inalienable del pueblo del Sáhara Occidental a la libre determinación y la independencia», e instó a Marruecos a que ponga fin a su ocupación del Sáhara Occidental.

22 Lee BuchHeIT, C., Secession: the legitimacy of self-determination, New Haven and London, Yale University Press 1978, pp. 11-16.

23 Cfr. Frank, Th. et al., The Territorial Integrity of Québec in the Event of the Attainment of Sovereignty - Experts Report. In Self-Determination in International Law: Quebec and Lessons Learned, 2000, ed. A.F. Bayefski, pp. 333-342, p. 335. 
En este contexto, el presente estudio se pregunta si en la actualidad Cataluña puede invocar y ejercer lícitamente el derecho a la autodeterminación de los pueblos, tal y como se regula, entiende y aplica en el derecho internacional actual o si, en su caso, existe el «derecho a separase unilateralmente del Estado» sin considerar la integridad territorial y la unidad política del Reino de España. Para dar respuesta fundada en el derecho internacional a esta cuestión, hay que analizar dos cuestiones importantes. La primera consiste en identificar el significado y alcance actual del derecho a la autodeterminación y si dicho derecho engloba el pretendido derecho a la secesión, bajos determinadas circunstancias o no. En la segunda se plantea si el derecho internacional vigente contempla el supuesto derecho a declarar unilateralmente la independencia y, en su caso, qué requisitos jurídicos deben satisfacerse para la validez de este tipo de acto unilateral, que conllevaría en consecuencia a la creación de un nuevo Estado. Como conclusión -puede adelantarse- que tanto las limitaciones externas como internas al derecho de autodeterminación, hacen que la reclamación de independencia de Cataluña sea contraria al derecho internacional vigente y que es imposible que este pueblo no-colonial obtenga por esta vía la independencia.

\section{SigNIFICADO Y ALCANCE DEL DERECHO A LA LIBRE DETERMINACIÓN DE LOS PUEBLOS}

En términos generales, cuando se invoca el derecho a la autodeterminación se está haciendo referencia al derecho de una persona o grupo a determinar qué camino quieren que siga su grupo, tanto para el presente como para el futuro. Es un concepto amplio que cubre a distintos tipos de personas y contextos, cuyo legítimo ejercicio puede dar lugar a la creación de un nuevo Estado independiente y soberano. Sin embargo, también puede tener como resultado final otras formas más limitadas de autonomía, pero sin llegar a gozar de todos los atributos de un Estado soberano. Por esta razón, el derecho a la autodeterminación es el derecho subjetivo de un grupo o pueblo para poder llegar a alcanzar, sin contradecir el orden internacional, un cierto grado de autonomía de su soberano ${ }^{24}, \mathrm{y}$ no solo como un principio central del derecho internacional.

24 Cfr. MÜLlerson, R., «Self-determination and secession: similarities and differences», en P. Hilpold, Autonomy and self-determination between legal assertions and utopian aspirations, Cheltenham UK, Edward Elgar Publishing, 2018, pp. 77-96. 
Con ocasión de la Opinión Consultiva sobre el Sáhara Occidental, la Corte Internacional de Justicia dio un nuevo enfoque al concepto, al sostener que el principio de autodeterminación podía definirse como la necesidad de prestar atención a la voluntad de los pueblos expresada libremente, y que su validez no se vería afectada por el hecho de que en ciertos casos la Asamblea General hubiera renunciado al requisito de consultar a los habitantes de un determinado territorio $^{25}$. Para la Corte, lo esencial del derecho a la autodeterminación era la obligatoriedad de actuar de acuerdo con la voluntad libremente expresa del pueblo saharaui ${ }^{26}$, en ese caso concreto, con independencia de que se decidiera la creación de un nuevo Estado, su integración en el Reino de Marrueco o su continuidad como colonia española. Como derecho subjetivo «colectivo» que es, por tanto, el derecho a la libre determinación de los pueblos obliga a la comunidad internacional a prestar atención a la voluntad libremente expresada de cada pueblo en cuestión, pero sin menospreciar el resto de requisitos jurídicos previstos en las normas internacionales. Otra característica destacable de la Opinión de la Corte es que no apuntó expresamente al «derecho» a la libre determinación, sino que habló del principio de la libre determinación ${ }^{27}$. Este pronunciamiento es de 1975, por lo que se comprende que la Corte evitase cuidadosamente hablar del derecho a la libre determinación seguramente por dos razones: una política y otra jurídica. En primer lugar, porque sería aconsejable despojar a la libre determinación de la connotación anterior -de derecho subjetivo exigible- como cualquier otro derecho reconocido en el orden internacional. Y segundo, porque según los Propósitos de la Carta de la ONU, su naturaleza jurídica respondía más a la de un «principio» y que a la de un «derecho». Nuestra sospecha se fundamenta en el hecho de que el Proyecto de Declaración de derechos y deberes de $\operatorname{los} \operatorname{Estados}^{28}$ de 1949 no hiciera

25 I.C.J. Report, 1975, de 16 de octubre de 1975 opinión consultiva sobre el Sahara Occidental, párrafo 59.

26 Sobre esta cuestión, algún autor ha resaltado la idea una autodeterminación devolutiva, que podría desembocar en autonomía. Cfr. SIMPSON, G. J., «The Diffusion of Sovereignty: Self-Determination in the Postcolonial Age», Stanford Fournal of International of International Law, vol. 32, 1996, p. 255.

27 El derecho exigiría, en la mayoría de las construcciones, una respuesta humana; con un principio, la necesidad de una respuesta humana específica es decididamente menos clara. Cfr., por ejemplo, Halpin, A., Rights and Law Analysis and Theory, Hart Publishing 1997, Ronald Dworkin, Taking Rights Seriously, Harvard University Press, 1978, p. 22 (defining principle as «a standard to be observed... because it is a requirement of justice or fairness or some other dimension of morality»)

28 A/RES/375, 6 diciembre 1949. 
referencia ni al derecho a la autodeterminación ni a las «obligaciones» de los Estados de respetarlo. De hecho, el Representante permanente de la Unión de Repúblicas Socialistas Soviéticas, Vladimir M. Koretsky, votó contra el borrador argumentando que «se desviaba de los principios fundamentales de las Naciones Unidas como la igualdad soberana de todos los Estados miembros y el derecho de auto-determinación de los pueblos» ${ }^{29}$.

Por lo general, cuando se invoca el derecho a la autodeterminación se pueden distinguir dos aspectos de su ejercicio: uno interno y otro externo. El primero -autodeterminación interna- hace referencia a varios derechos políticos y sociales, como por ejemplo, el derecho de las personas de un Estado a gobernarse sin interferencia externa de terceros soberanos. En cambio, la autodeterminación externa se refiere a la independencia o secesión legal de un pueblo en relación con la soberanía de otro. Sería el resultado fáctico final del derecho de los pueblos a determinar su propio estatus jurídico y político, sin injerencia extranjera. Sin embargo, el efecto útil de esta distinción es muy reducido o casi inexistente en la práctica internacional. Como sostuvo Martti Koskenniemi, existirían esencialmente dos versiones de autodeterminación, que teóricamente compitan entre sí, pero que se solapan en la práctica ${ }^{30}$. Existe una «buena» versión de la autodeterminación que apela a los instintos democráticos y al sentido de imparcialidad, $\mathrm{y}$ hay una versión «menos benigna» que apela a nuestros instintos nacionalistas, aislacionistas y excluyentes. En última instancia, la autodeterminación «apoya y desafía a la condición de Estado», por lo que no puede aplicarse constantemente el derecho a la autodeterminación, cuando no existe distinción entre ambos elementos. Cuando se habla de autodeterminación se está haciendo referencia a esa autodeterminación externa que engloba la interna. Esta ambigüedad terminológica, parece esconder -como señala Peter Hilpold- una intención precisa de crear áreas grises y significados dobles para poder utilizar ambas formas indistintamente y satisfacer intereses que son per se diametralmente opuestos ${ }^{31}$. Más allá de estas afirmaciones, la autodeterminación externa se compone esencialmente

29 Sobre los antecedes y contexto histórico en el que se firmó la Carta y el principio a la libre determinación de los pueblos, cfr. en este mismo Anuario, a RuIz Miguel, C., «El principio y derecho de autodeterminación y el pueblo del Sahara Occidental», Anuario Español de Derecho Internacional, vol. 31, 2015, pp. 267-296, p. 273.

30 Cfr., Koskenniemi, M., «National Self-Determination Today: Problems of Legal Theory and Practice», International and Comparative Law Quarterly, vol. 43, 1994, pp. 241, 249.

31 Cfr. Hipold, P., «Secession in international Law», en Kosovo and International Law, Brill, 2012, p. 49. 
de dos elementos: la protección de la soberanía nacional (un derecho que sería autosuficiente como tal y que no necesariamente requeriría más confirmación por un derecho a la autodeterminación) y el Derecho colonial a la autodeterminación.

\section{MARCO JURÍDICO DEL DERECHO A LA LIBRE DETERMINACIÓN}

\section{DE LOS PUEBLOS}

Las raíces de este derecho «colonial» a la autodeterminación se encuentran en la Carta de las Naciones Unidas, en particular en sus artículos 1 y 55, aunque la propuesta de Dumbarton Oaks no lo mencionó. El segundo propósito de esta Organización consiste en «desarrollar relaciones amistosas entre las naciones basadas en el respeto del principio de igualdad de derechos y autodeterminación de los pueblos...» (art. 2. ONU), mientras que de art. 55 ONU contempla expresamente, que:

Con el propósito de crear las condiciones de estabilidad y bienestar necesarias para las relaciones pacíficas y amistosas entre las naciones, basadas en el respeto al principio de la igualdad de derechos y al de la libre determinación de los pueblos, la Organización promoverá... progreso y desarrollo económico y social... el respeto universal a los derechos humanos y a las libertades fundamentales de todos, sin hacer distinción por motivos de raza, sexo, idioma o religión, y la efectividad de tales derechos y libertades.

También los artículos 2 y 53 de la Carta crean obligaciones directas para los Estados en relación con la efectiva aplicación de las disposiciones de los artículos 1 y 55. Además, los capítulos XI, XII y XIII, que se ocupan de los territorios no autónomos y bajo administración fiduciaria, proclaman implícitamente este principio e impone a los Estados miembros la obligación de aplicarlo. Además, los Estados responsables de la administración de los territorios no autónomos deben «desarrollar el autogobierno, teniendo debidamente en cuenta las aspiraciones políticas de los pueblos y deben asistirlos igualmente en el desarrollo progresivo de sus instituciones políticas libres ${ }^{32}$.

32 Dado que el objetivo del artículo 73 es «garantizar, con el debido respeto a la cultura de los pueblos interesados, su avance político, económico, social y educativo, su trato justo y su protección contra los abusos (y] desarrollar el autogobierno para tener debidamente en cuenta las 
Entre las muchas resoluciones aprobadas en la Asamblea General de las Naciones Unidas sobre la descolonización y el principio de la libre determinación de los pueblos ${ }^{33}$, hay que destacar al menos tres, a mi juicio, que marcan con claridad los requisitos jurídicos esenciales para su lícita y legítima invocación en la actualidad. Las principales resoluciones son: la Declaración sobre la concesión de la independencia a los paises y pueblos coloniales (Resolución 1514 (XV), conocida también como la Carta Magna de la descolonización ${ }^{34}$; la Resolución 1803 (XVII) de 14 de diciembre de 1962 relativa a la soberanía permanente de los pueblos a sus riquezas y recursos naturales debe ejercerse en interés del desarrollo nacional y del bienestar del pueblo del respectivo Estado; y la Declaración sobre los principios de derecho internacional relativos a las relaciones amistosas y la cooperación entre los Estados de conformidad con la Carta de las Naciones Unidas de la Resolución 2625 (XXV) de 1970 de la AG, cuyo contenido fue corroborado posteriormente con motivo del quincuagésimo aniversario de las Naciones Unidas de $1995^{35}$.

El tenor de la primera de ellas -la Resolución 1514- es claro y contundente, y asienta las bases del derecho a la autodeterminación como un derecho que corresponde a «todos los pueblos...; para que determinen libremente su condición política y persiguen libremente su desarrollo económico, social y cultural». Afirmaba asimismo que la inadecuada preparación política, económica, social o educativa «nunca debería servir de pretexto para retra-

aspiraciones políticas de los pueblos y ayudarlos a desarrollar progresivamente sus instituciones políticas libres, de acuerdo con las circunstancias particulares de cada territorio y sus pueblos y sus diferentes etapas de avance». Cfr. además Simma, B. et al. (eds.), The Charter of the United Nations. A Commentary, vol. II, Oxford, Oxford University Press, 2012, pp. 1687 y ss.

33 Sobre el debate acerca del potencial efecto jurídico de las Declaraciones de le Asamblea General existen diversas teorías en la doctrina. Por ejemplo, entre las escuelas «tradicionales», cfr., Gross, L., Essays on International Law and Organization, Transnational Publishers 1984, pp. 214220; Haight, G.W., «The New International Economic Order and the Charter of Economic Rights and Duties of States», International Law, vol. 9, 1975, pp. 591, 597. Entre las escuelas más «progresistas», cfr., entre otros, OBED Y. A., The Legal Significance of The Declarations of The General Assembly of The United Nations, Springer Verlag, 1966, p. 2; SLOAN, B., United Nations General Assembly Resolutions in Our Changing World, 1991, pp. 53, 76. SAFFO, P. L., «The Common Heritage of Mankind: Has the General Assembly Created a Law to Govern Seabed Mining?», Tulane Law Review, vol. 53, 1979, pp. 492-508, quien llega a sugerir que «[i]t is axiomatic that the General Assembly possesses no formal competence to attribute binding legal force to externally directed resolutions. At the same time, however, it is equally true that such recommendations often have undeniable legal or political effects quite out of proportion to their formal recommendatory status.»

34 Aprobada por 89 votos a favor, ninguno en contra y 9 abstenciones.

35 A/ RES/ 50/6, de 9 de noviembre de 1995. 
sar la independencia», por lo que prohibía todos los intentos dirigidos a «la interrupción parcial o total de la unidad nacional y la integridad territorial» de cualquier Estado. Como ha destacada la doctrina, la Resolución 1514 y los Pactos Internacionales de Derechos Humanos «proporciona la base para la aceptación incuestionable en el derecho internacional que el derecho a la autodeterminación se aplica solo a los pueblos bajo dominación colonial y alienígena ${ }^{36}$. El principio de autodeterminación pasa al plano positivo convencional en unos instrumentos jurídicos dedicados a los derechos humanos, estableciéndose -por lo tanto- un vínculo muy estrecho entre el derecho de los pueblos a disponer de sí mismos y los derechos humanos. Ahora bien, según la Resolución 1514, el concepto de «pueblo» abarca «un tipo específico de comunidad humana que comparte un deseo común de establecer una entidad capaz de funcionar para asegurar un futuro común».

Los derechos económicos que conlleva el derecho a la libre determinación de los pueblos quedaron claramente establecidos en la llamada doctrina de la soberanía permanente sobre los recursos naturales, y que no deja de ser un elemento fundamental del derecho de los pueblos a disponer de sí mismos, tal y como está recogida en la Resolución 1314 (XIII), y sobre todo en la Resolución 1803 (XVII) de 14 de diciembre de 1962. Y es que en esta materia, estas resoluciones consideran al «pueblo» como el beneficiario exclusivo y directo de esos recursos antes de su independencia, algo que por ejemplo es el gran drama en el caso del Sahara Occidental y que Marruecos y sus socios europeos está violando abiertamente, sin que las Naciones Unidas se pronuncien al respecto.

La tercera Resolución clave en esta materia es la Resolución 2625 (XXV), de 1970 que bajo el título de la Declaración sobre los principios de derecho internacional sobre relaciones amistosas fue aprobada por unanimidad en la Asamblea General gracias al incremento considerable de sus miembros. Sus contenidos específicos configuran el derecho de todos los pueblos a determinar su destino político, económico, social y cultural sin ninguna interferencia externa. Este enfoque constituye una contribución significativa al derecho internacional

36 Cfr. Gros Espiell, H., The Right to Self-Determination: Implementation of United Nations Resolutions 11979 U.N. Sales No. E. 79 XIV 5 paragraph 56. El profesor Gros Espiell fue el Relator Especial de la Subcomisión de Prevención de Discriminaciones y Protección de las Minorías de los Estados Unidos. Su informe establece la definición, el alcance y la naturaleza jurídica del derecho de los pueblos bajo dominación colonial a la libre determinación, y los medios por los cuales la comunidad internacional ha supervisado y promovido ese derecho. 
contemporáneo, ya que el sometimiento de los pueblos a la subyugación, la dominación y la explotación de extranjeros constituye un obstáculo importante para la promoción de la paz y la seguridad internacionales ${ }^{37}$. Su contenido ha sido aceptado en la práctica como vinculante y, además, se ha corroborado en la Declaración del Quincuagésimo Aniversario, porque reafirma, incluso con la misma redacción, el derecho a la libre determinación de la Resolución 2625 que es a su vez considerada norma de ius cogens ${ }^{38}$.

En la Resolución 2625 se enfatiza que la autodeterminación es un derecho y no solo un mero concepto político; impone a cada Estado el deber de promover la igualdad de derechos y la autodeterminación de los pueblos, pero distingue entre la negación de los derechos humanos y la negación del derecho a la libre determinación al afirmar que «el sometimiento de los pueblos a la subyugación extranjera, la dominación y la explotación constituye una violación del principio [de igualdad de derechos y de libre determinación], así como una negación de los derechos humanos fundamentales». Su párrafo 4 establece los cuatro modos en que las personas pueden hacer valer su derecho a la libre determinación: (1) el establecimiento de un Estado soberano o independiente; (2) la libre asociación con un Estado independiente; (3) la integración en un independiente Estado; o (4) la aparición de cualquier otro estatus político libremente determinado por un pueblo. Es importante tener en cuenta que esta disposición está dirigida a las personas mismas que constituyen un pueblo y no a los Estados o naciones, lo que implica que existe un derecho a la autodeterminación por parte de un «pueblo» ${ }^{39}$. Además -como

37 Cfr. Preámbulo de la Resolución 2625 (XXV), de 1970.

38 Cfr. entre otros, Brownlie, I., Principles of Public International Law, 4th ed. 2000, Oxford, Oxford University Press p. 513; CASSESE A., «Article 1, paragraphe 2», en La Charte des Nations Unies. Commentaire article par article, ed. J.P. Cot and A. Pellet, 2nd ed., 1991, Paris/Brussels, Economica/Bruylant, pp. 39-45, p. 45; Crawford J., The Rights of Peoples, Oxford, Clarendon Press, 1998, p. 166; Gros EsPIELl H., «En torno al derecho de la libre determinación de los pueblos», ADI 3, 1976, pp. 49 74, p. 68; Hannum H., H. 1990. Autonomy, Sovereignty, and Self-Determination: The Accommodation of Conflicting Rights, Philadelphia, University of Pennsylvania Press, 1990, p. 45; KIss, A., «The Peoples' Right to Self-Determination», Human Rights Law Fournal, vol. 7, 1986, pp. 165-175, p. 174; OETER S., «The Role of Recognition and Non-Recognition with Regard to Secession. In Self-Determination and Secession in International Law», C. Walter. et al. (ed.), Oxford, Oxford University Press, 2014, pp. , 45-67, p. 52.

39 Cfr., BuchHeIT, L.C., Secession: the legitimacy of self-determination, 1978, pp 92. «However, when the People and the Nation are one and the same, and when a people has established itself as a State, clearly that Nation and that State are, as forms or manifestations of the same People, implicitly entitled to the right of self-determination; GROS EsPIELL, H., The Right to Self-Determination: Implementation of United Nations Resolutions 11979 U.N. Sales No. E. 79 XIV 5 párrafo 56. 
no podía ser de otra forma- en consonancia con el orden internacional creado en la Carta de la ONU de 1945 -el párrafo 5 de la Resolución 2625 impone a los Estados el deber de abstenerse de usar la fuerza para privar a los pueblos de su derecho a la autodeterminación y da derecho a las personas que están sujetas a tal acción forzosa por parte de un Estado para recibir apoyo y hacer frente a dicha fuerza-. Finalmente, y lo más importante a efectos de este estudio, es que su párrafo 7 reconocer que la secesión puede ser una opción legítima, pero solo bajo ciertas circunstancias.

\subsection{Significado del concepto «pueblo»}

La palabra «pueblo» se menciona en el preámbulo de la Declaración, sin embargo, la primera aplicación significativa del término aparece en el Principio $\mathrm{V}$, párrafo 1:

En virtud del principio de igualdad de derechos y autodeterminación de los pueblos consagrados en la Carta de las Naciones Unidas, todos los pueblos tienen derecho a determinar libremente, sin injerencias externas, su condición política y perseguir su desarrollo económico, social y cultural, y todo Estado tiene el deber de respetar este derecho de conformidad con las disposiciones de la Carta.

Como se puede observar, «Estado» y «pueblo» son dos conceptos separados, y en relación con el segundo, existe un claro nexo entre «pueblo» $\mathrm{y}$ «desarrollo cultural», de tal forma que éste forma parte inherente del derecho de «todos los pueblos» a disfrutar del derecho a la libre determinación. El término «pueblo» es una expresión de aplicabilidad amplia y general que se extiende al contexto colonial y no-colonial ${ }^{40}$. Como señala Anderson ${ }^{41}$, se llega a una con-

40 Véase, Sukovid, O., «Principle of Equal Rights and Self-Determination of Peoples», en M. Sukovid (ed.) Principles of International Law Concerning Friendly Relations And Cooperation, 1972, pp. 323, 342, quien al considerar el concepto de pueblo en esta Resolución señala que «[i]n the end the opinion prevailed that the right of peoples to self-determination had a universal character and that this right belonged to all peoples regardless of whether they had gained independence or not.» (enfasis original).

41 ANDERSON, G., «Unilateral non-colonial secession in International Law and Declaratory General Assembly Resolutions: textual content and legal effects», Denver Fournal of International Law and Policy, vol. 41, 2012-2013, pp. 345-395, pp. 350-353. 
clusión similar al examinar el Principio V, párrafo 2, que nuevamente menciona al «Estado»y al «pueblo» como dos conceptos distintos. Más allá del contexto colonial, se hace referencia a que «la sujeción de los pueblos a la subyugación, la dominación y la explotación extranjera» es contraria a la Carta de la ONU. Esta última frase parece indicar que los pueblos también pueden existir en un contexto no colonial, ya que las situaciones de «subyugación extranjera, dominación y explotación» no son exclusivas de la colonización. El Principio V, párrafo 4, reitera el contenido del Principio VI de la Resolución $1541^{42}$ con respecto a los métodos por los cuales un pueblo puede ejercer su derecho a la libre determinación externa. Sin embargo, a diferencia del Principio VI, el párrafo 4 de la Resolución 2625 no busca explícitamente limitar la aplicación de su contenido a los pueblos coloniales. Esta diferencia es crucial, ya que abre la posibilidad de que el párrafo 4 de la Resolución 2625 se aplique a los pueblos no coloniales. Además, en el párrafo 5 de la Resolución 2625, reitera el deber de los «Estados» de abstenerse de tomar medidas que priven a los «pueblos» de su derecho a la libre determinación. Esta terminología y su interpretación sistemática reafirman implícitamente que los Estados y los pueblos son dos conceptos distintos y que ambos pueden darse en un contexto colonial y en otro no-colonial.

La sistemática interna de la Resolución 2625 es lógica y ordenada. Una vez establecido que el derecho de la libre determinación de los pueblos puede invocarse por los pueblos coloniales y los no-coloniales, ahonda por separado en cada uno de estos dos escenarios. El párrafo 6 afecta exclusivamente a los pueblos coloniales en el sentido de que «el territorio de una colonia u otro Territorio no autónomo tiene, según la Carta, un estado separado y distinto del territorio del Estado que lo administra. Sin embargo, el párrafo 7 de la Resolución 2625 contempla condiciones y límites específicos para el ejercicio del derecho de autodeterminación de un pueblo no-colonial. En concreto dicho párrafo reza así:

Ninguna de las disposiciones de los párrafos precedentes se entenderá en el sentido de que autoriza o fomenta cualquier acción encaminada a quebrantar o menospreciar, total o parcialmente, la integridad territorial de

42 Resolución 1541 (XV), de 15 de diciembre de 1960, relativa a los Principios que deben guiar a los miembros para determinar si existe o no una obligación de transmitir la información solicitada en virtud del Artículo 73.e) de la Carta. Esta resolución sirvió como contraparte interpretativa de la Declaración de 1960 sobre el otorgamiento de la independencia a los países y pueblos coloniales. Resolución 1514 (XV), de 14 de diciembre de 1960 de la Asamblea General. 
Estados soberanos e independientes que se conduzcan de conformidad con el principio de la igualdad de derechos y de la libre determinación de los pueblos antes descrito y estén, por tanto, dotados de un gobierno que represente a la totalidad del pueblo perteneciente al territorio, sin distinción por motivos de raza, credo o color.

Como se puede apreciar, este criterio afecta a los «Estados soberanos e independientes», y no a los territorios no autónomos. Aunque se podría argumentar que en última instancia esta referencia atañe a los poderes metropolitanos responsables de los territorios no autónomos (es decir, a los Estados), éste no parece ser el objetivo principal de este párrafo $7^{43}$. Dejando de lado algunos problemas de redacción, es habitual referirse este párrafo 7 como la «cláusula de salvaguarda de la integridad territorial de los Estados», que puede aplicarse igualmente como base jurídica del derecho a una declaración unilateral de independencia, siempre y cuando se cumplan las condiciones prevista en dicha cláusula $^{44}$. No existe un derecho absoluto a la secesión; sino que solo podrá admitirse cuando se cumplan los requisitos específicos y, en casos extremos, como solución final o último recurso $0^{45}$.

\subsection{El derecho de los pueblos a una secesión no colonial unilateral}

El párrafo 7 de la Resolución 2625 -citado anteriormente- no responde claramente si existe el derecho de declarar la independencia de un pueblo nocolonial o no. La falta de claridad reside en la redacción de la propia Declaración. Contiene, no obstante, los elementos necesarios para determinar las circunstancias excepcionales que habilitarían un pueblo a invocar de forma

43 ANDERSON, G., «Unilateral non-colonial secession in International Law and Declaratory General Assembly Resolutions: textual content and legal effects», Denver Fournal of International Law and Policy, vol. 41, 2012-2013, p. 352.

44 Cfr., VAN DEN Driest, S.F.., «Crimea's Separation from Ukraine: An Analysis of the Right to Self-Determination and (Remedial) Secession in International Law», Netherlands Inteernational Law Review, vol. 62, 2015, pp. 329-363, p. 338; JACOBS, D., «International Court of Justice. Accordance with International Law of the Unilateral Declaration of Independence in Respect of Kosovo, Advisory Opinion of 22 July 2010», International \& Comparative Law Quarterly, vol. 60, 2011, pp. 799-810, p. 804.

45 Cfr. por ejemplo, Escudero Espinosa, J. F., Self-Determination and Humanitarian Secession in International Law of a Globalized World, Springer Verlag, 2107, quien incluso afirma la existencia de una secesión humanitaria, pp. 166-17 
unilateral su deseo de secesión. Los trabajos preparatorios de la Resolución 2625 revelan que había dos posiciones radicales diferentes: por una parte, la de aquellos Estados que favorecían la inclusión de un derecho a la secesión unilateral y por otra, la de sus detractores. Los Estados del antiguo bloque comunista, por ejemplo, argumentaban que el derecho a la autodeterminación incluía un derecho inherente a declarar de forma unilateral la independencia o la secesión ${ }^{46}$.

Como ya se vio anteriormente, el párrafo 4 de la Resolución 2625 enumera las formas en que un pueblo puede ejercer su autodeterminación externa, en concreto, mediante el establecimiento de «un Estado soberano e independiente, la libre asociación o integración con un Estado independiente», así como también se podría adoptar cualquier otro estatus político libremente determinado por el pueblo». Pero este precepto no restringe su aplicación a un tipo determinado de pueblo -colonial o no colonial- sino que más bien su silencio es deliberado. Nada obsta, por consiguiente, a que la autodeterminación externa se pueda aplicar tanto a los pueblos coloniales como a los no coloniales.

En el caso de pueblo no-coloniales y no autónomos, la Resolución 2625 otorga el mismo derecho de autodeterminación externa, incluso bajo la forma de secesión, pero teniendo en cuenta la llamada «cláusula de salvaguardia» del párrafo 7 de la citada Resolución. Así la práctica internacional confirma la aparición de nuevos Estados como resultado de la secesión unilateral no colonial ${ }^{47}$. Como ya apuntaba Kohen, la secesión podría definirse como la creación de una nueva entidad independiente mediante la separación de parte del territorio y la población de un Estado existente, sin el consentimiento de este último ${ }^{48}$. En este

46 BuCHHEIT, L.C., Secession: the legitimacy of self-determination, 1978, p. 91.

47 La secesión puede ser unilateral o consensual. En el caso de la primera, la secesión ocurre sin el consentimiento del estado existente. Por el contrario, la secesión consensual recibe el imprimátur del estado existente. La secesión consensual puede subdividirse conceptualmente en secesión constitucional y negociada políticamente. La secesión puede ocurrir en un contexto colonial o no colonial, ya que cualquier nueva afirmación de soberanía sobre un territorio colonial o parte de un estado existente implica una modificación de la soberanía del poder metropolitano o del estado existente, respectivamente. Entre quienes proponen que la secesión puede dares en un contexto colonial o no colonial, cfr., EsCUDERo EsPINOSA, J. F., Self-Determination and Humanitarian Secession in International Law of a Globalized World, Springer Verlag, 2107; CRAWFORD, J., The creation of States in International Law, $2 \mathrm{~d}$ ed., 2007 pp. 330, y 370; OUGUERGOUZ, F., The African Charter on human and peoples' rights: a comprebensive agenda for buman dignity and sustainable democracy in Africa, Brill, 2003, pp. 235-236.

48 Kohen, M., «Introduction», en M. Kohen (ed.), Secession. International Law Perspectives, Cambridge and New York, Cambridge University Press, 2006, p. 3. 
sentido se entienden los casos de Bangladesh (Pakistán), Eritrea (Etiopía), Bosnia-Herzegovina, Croacia, Macedonia, Montenegro, Eslovenia, Serbia y Kosovo (Yugoslavia) ${ }^{49}$. Sin embargo, desde algún sector doctrinal se apuntó hace ya unas décadas que de acuerdo con la redacción y el espíritu de la Resolución 2625, las Naciones Unidas habrían establecido que el principio de libre determinación era el principal y exclusivo vehículo para la descolonización, pero que la citada Resolución no amparaba una secesión ${ }^{50}$. En su origen no se concebía que el derecho de autodeterminación pudiese quebrantar al Estado, aunque estuviese ejerciendo una dominación extranjera sobre otro territorio. Esta postura de «anti-secesión» se fundamentaba en el hecho de que la secesión rompe las fronteras y las estructuras políticas de los Estados independientes, que de permitirse se estría violando el principio de la integridad territorial y política. Sin embargo, este principio constituye un límite al derecho a la libre determinación; ya que más allá del contexto del colonialismo, el «derecho de autodeterminación» no equivale a un «derecho a la independencia».

Esto es así, por un lado, porque el derecho internacional es neutral y ni regula ni prohíbe una eventual secesión unilateral. El derecho internacional reconoce el derecho unilateral a separarse solo en ciertas circunstancias excepcionales relacionadas con el derecho a la libre determinación, tal y como fue confirmado por la Corte Suprema de Canadá en el caso de Quebec (1998) y posteriormente por la opinión consultiva de Kosovo de la Corte Internacional de Justicia (2010). En efecto, la Corte Suprema de Canadá en el caso de Quebec indicó que «el derecho internacional puede adaptarse para reconocer una realidad política y/o objetiva, independientemente de la legalidad de los pasos que conduzcan a su creación ${ }^{51}$. De hecho, si una secesión es exitosa en las calles, bien podría conducir a la creación de un nuevo Esta$\mathrm{do}^{52}$. Del caso de Quebec se puede extraer también la conclusión de que la secesión también podría aplicarse como último recurso en aquellos casos en los que se intente bloquear el derecho de los pueblos a la autodeterminación interna ${ }^{53}$, siempre y cuando los Estados reconozcan ampliamente la reclamación de soberanía. El Tribunal Supremo de Canadá ha llegado a la conclusión

49 En relación con Kosovo, cfr., Hilpold, P. (ed.), Kosovo and International Law, Nijihoff, 2012.

50 Gros Espiell, H., The Right to Self-Determination: Implementation of United Nations Resolutions 11979 U.N. Sales No. E. 79 XIV párrafo 60.

51 Secession of Quebec, [1998] 2 S.C.R. 217, párrafo 141.

52 Ibid., párrafo 142.

53 Supreme Court of Canada Reference re Secession of Quebec, [1998] 2 SCR, párrafo 348 y ss. 
de que «la viabilidad de un posible Estado en la comunidad internacional depende, por razones prácticas, del reconocimiento por parte de terceros Estados», a pesar de que no están obligados a prestar tal reconocimiento ${ }^{54}$. Es más, solo bajo ciertas circunstancias existe la obligación de no-reconocer a un nuevo Estado, tal y como se desprende del Artículo 41 del Proyecto de artículos de la Comisión de Derecho Internacional sobre la responsabilidad internacional del Estados por actos ilícitos, puesto que, en efecto, no se contempla literalmente la obligación de negar el reconocimiento al Estado surgido de una declaración unilateral de independencia. En cambio, impone textualmente la obligación a los Estados de no reconocer como lícita una situación creada por una violación grave en el sentido del artículo 40, ya que también obliga a no prestar ayuda o asistencia para mantener esa situación (art. 41.2 Proyecto). De esta forma, una violación de jus cogens genera la obligación de erga omnes de negar el reconocimiento ${ }^{55}$. Esta obligación de no reconocimiento en respuesta a violaciones graves de obligaciones dimanantes de normas imperativas cuenta con el apoyo en la práctica internacional y las decisiones de la Corte Internacional de Justicia ${ }^{56}$. La Corte Internacional de Justicia ya sostuvo de forma indirecta en la Opinión de Kosovo que nada en el derecho internacional prohíbe a un pueblo dentro de un Estado declarar su secesión. Pero la Corte no ahondó en las cuestiones sustanciales y ni explicó el papel del derecho internacional en el proceso de creación de nuevos Estados fuera de las situaciones coloniales. La Corte se limitó a responder a las preguntas de la Asamblea General en términos de violación de las obligaciones, sin entrar a abordar la cuestión de la existencia de un derecho (o no) a declarar la independencia y menos aún de la extensión de ese derecho o la

54 Cfr., Talmon, S., Kollective Nichtanerkennung illegaler Staaten, Mohr Siebeck, 2004, p. 103.

55 UN Doc. A/RES/ 56/83, de 21 de diciembre de 2001, sobre la Responsabilidad internacional de los Estados por actos ilícitos.

56 Cfr., por ejemplo, I.C.J. Reports 1986, sobre las actividades militares y para militares en y contra Nicaragua, párrafo 188 en donde la Corte señalo que el consentimiento unánime de los Estados a aquella declaración podía entenderse como la aceptación de la validez de la norma o el conjunto de normas proclamados por la resolución. Tras la declaración por el Iraq de una «fusión total y eterna» con Kuwait, el Consejo de Seguridad, en su Resolución 662 (1990), de 9 de agosto de 1990, decidió que la anexión carecía «de validez jurídica y ha de considerarse nula y sin valor», y exhortó a todos los Estados, organizaciones internacionales y organismos especializados a no reconocer esa anexión y abstenerse de todo acto o transacción que pudiera interpretarse como un reconocimiento directo o indirecto de la anexión. Recuérdese asimismo, como en la opinión consultiva de la Corte sobre el asunto Namibia es igualmente clara por cuanto exhorta a que no se reconozca la situación, I.C.J. Reports, 1971, opinión consultiva, párrafo 126. 
validez o invalidez de la eventual declaración unilateral ${ }^{57}$. En mi opinión, la Corte desaprovechó una buena oportunidad (una vez más) de aclarar el papel del derecho internacional en el proceso de creación de Estados fuera del contexto de la descolonización.

Por otro lado, puesto que la ilegalidad de una declaración unilateral de independencia solo puede provenir de una violación de una norma de ius cogens, hay que recordar que la integridad territorial no corresponde a este tipo de normas. El principio de la integridad territorial de los Estados está bien establecido en la Carta de las Naciones Unidas y protegido por otras normas, como la prohibición de injerencia en la jurisdicción interna de los Estados ${ }^{58} \mathrm{y}$ prohibición de la amenaza o el uso de la fuerza ${ }^{59}$.

Ahora bien, junto a los efectos externos que ostenta la integridad territorial, este principio también tiene efectos internos, que pueden contradecir -aparentemente- otros principios del orden internacional, como el de la autodeterminación de los pueblos ${ }^{60}$. Ante tal situación, hay que partir de la premisa que el carácter unilateral de una declaración de independencia por sí solo no hace que el nuevo Estado sea ilegal. Obviamente, la autodeterminación externa está en total conflicto con el principio de la integridad territorial de los Estados; pero la integridad territorial de los Estados no es un obstáculo insalvable para los pueblos que tienen derecho a ejercer el derecho a la libre determinación (interna y externa) de conformidad con el derecho internacional.

La llamada «cláusula de salvaguardia» del párrafo 7 de la Resolución 2625 indica que el principio de integridad territorial del Estado limita el derecho a la autodeterminación, siempre y cuando un Estado posea un gobierno que represente a la totalidad de los pueblos pertenecientes a su territorio sin discriminación ni distinción alguna. Solo aquellos Estados que se comporten de acuerdo con los Principios de la Carta de las Naciones Unidas se les garantizará su inte-

57 Kohen, M., 2013 ASIL Proceedings, pp. 218-219; Urrutia Libarona, I., «Territorial Integrity and Self-determination: the approach of the International Court of Justice in the Advisory Opinion on Kosovo», REAF, num. 126, October 2012, pp. 107-140, p. 123; OETER, S., «Secession, territorial integrity and the role of Security Council», en Kosovo and International Law, Peter Hilpold (ed.), p. 112; GATTINI, A., «You say you'll change the Constitutions». The ICJ Opinion and the non-stat entities in the Kosovo Advisory Opinion», en Kosovo and International Law, Peter Hilpold (ed), pp. 235 y 239.

58 Malcolm, N. S., International Law, Cambridge, Cambridge University Press, 2003, p. 443 y ss.

59 CORTEN, O., «Territorial Integrity Narrowly Interpreted: Reasserting the Classical Inter-Sate Paradigm of International Law», Leiden Fournal of International Law, 24, 2011, p. 89.

60 I.C.J. Reports, 1986, en el asunto de Burkina Faso v. Mali pp. 554; 80 ILR, p. 469 
gridad territorial, que prevalecerá frente al principio de la libre determinación. Por el contrario, si un Estado no representa a toda la población, o discrimina a alguno de sus grupos nacionales, tales grupos tendrían el derecho de decidir su futuro político creando un nuevo Estado independiente. Estas disposiciones son clave para la correcta conjugación de la integridad territorial del Estado y el derecho a la libre determinación. Suponen la piedra de toque que debe medirse caso a caso; ya que tal y como expresa el citado párrafo 7 de esta Resolución, «nada en los párrafos anteriores debe interpretarse como una autorización o fomento del desmembramiento o deterioro de la unidad territorial o política de los estados soberanos e independientes». Se hace una advertencia similar en el párrafo 8 de la misma Resolución, que obliga a los Estados a abstenerse de realizar acciones encaminadas a interrumpir parcial o totalmente la unidad nacional y la integridad territorial de cualquier otro Estado o país. La esencial de esta cláusula de salvaguarda radica en que el Estado que «cumpla» con los estándares de derechos y libertades de sus pueblos queda amparado por el orden internacional frente a posibles violaciones de su integridad territorial y unidad política. De ahí que algún autor sostenga que el Estado cumplidor disfrutará de «la garantía de la santidad» de sus fronteras e independencia política ${ }^{61}$.

Pero del análisis de la cláusula de salvaguarda se desprende igualmente que denominada secesión correctiva o remedial seccession no es un derecho; sino solo y exclusivamente una consecuencia de la lectura invertida de dicha cláusula. Sin embargo, no existe una práctica estatal que apoye una lectura invertida de esta cláusula, que permita afirmar un hipotético derecho a la secesión, cuando el Estado no actúa en representación de todos pueblos conforme al Derecho ${ }^{62}$.

\section{SObRE LA SECESIÓN UNILATERAL DE UN PUEBLO NO-COLONIAL COMO MEDIDA DE ÚLTIMO RECURSO}

El derecho internacional relativo a la autodeterminación garantiza al Estado que se comporta de conformidad con el principio de igualdad de derechos y autodeterminación de los pueblos su integridad territorial o unidad política.

61 Cfr., BuchHeIT, L. C., Secession: the legitimacy of self-determination, 1978, pp. 91-92.

62 Cfr. Escudero Espinosa, J. F., Self-Determination and Humanitarian Secession in International Law of a Globalized World, Springer Verlag, 2017, p. 46 y ss. 
En cambio, si no representa a toda la población o discrimina por «raza, credo o color», actúa de forma contraria a la autodeterminación interna y, por tanto, dicho pueblo puede aspirar a la externa.

La doctrina acepta por unanimidad que las palabras «raza», «credo»y «color» recogidas en dicha cláusula abarcan claramente la discriminación racial, lingüística, cultural, consuetudinaria y religiosa ${ }^{63}$. Por lo tanto, podría interpretarse que la frase «sin distinción de raza, credo o color» ha sido reemplazada hoy por la expresión más amplia «sin distinción de ningún tipo de discriminación». El artículo 1 de la Declaración del Quincuagésimo Aniversario de la ONU de 1995 elimina la ambigüedad y el tedio interpretativo asociado con las palabras «raza», «credo» $\mathrm{o}$ «color», al referirse a «la igualdad de derechos... sin distinción alguna»; confirmando así que cualquier forma de discriminación contra un pueblo es inaceptable. Esto incluiría, por supuesto, un amplio espectro de otro tipo de abusos contra los derechos humanos más fundamentales del grupo de población afectada, ya sea de forma moderada (discriminación política, cultural y racial) o grave (limpieza étnica, asesinatos en masa y genocidio). La discriminación tiene un amplio ámbito operativo y no se limita simplemente a regímenes racialmente discriminatorios, como fue en su día el régimen de apartheid de Sudáfrica.

Pero esta aspiración, derecho a la libre determinación no es un derecho general y absoluto, sino uno específico y de carácter excepcional, regulado en la llamada cláusula de salvaguardia de la Resolución 2625. No se puede «desmembrar o menoscabar, total o parcialmente» la integridad territorial y la unidad política de los Estados soberanos sin más. El derecho de autodeterminación no «legaliza» cualquier movimiento separatistas o secesionista de un Estado, sino que opera como último recurso solo en determinados casos. Pues, en efecto, el propósito de esta cláusula era restringir el alcance de la autodeterminación, no expandirla. Como señala Stefan Oeter la cuestión es saber cuándo y bajo qué condiciones es posible ejercer esta autodeterminación externa ${ }^{64}$. La doctrina mayoritaria niega la existencia de un derecho a la secesión «como último remedio» cuando falla la autodeterminación interna ${ }^{65}$. Sin embargo,

63 Cfr., Cassese, A., The Self-Determination of Peoples. In The International Bill of Rights: The Covenant on Civil and Political Rights, ed. L. Henkin, 95-113. New York, Columbia University Press, 1991, p. 78.

64 Cfr., OETER, S., «Secession, territorial Integrity and the Security Council», en Kosovo and International Law, Peter Hilpold (ed.), p. 117.

65 Crawford, J., The Creation of States in International Law, 2nd ed., Oxford, Clarendon Press, pp. 388-402. 
bajo ciertas circunstancias muy específicas, el derecho a la autodeterminación interna podría transformarse en un derecho «de emergencia» para la creación de un nuevo Estado independiente ${ }^{66}$. Esta secesión de salvación o de recuperación se concibe como una versión extrema de la autodefensa colectiva. En consonancia con estos planteamientos teóricos, el Juez Yusuf dio una explicación muy clara en su Opinión Separada en la Opinión Consultiva de Kosovo:

This provision [cláusala de salvaguarda de la Resolución 2625] makes it clear that so long as a sovereign and independent State complies with the principle of equal rights and self-determination of peoples, its territorial integrity and national unity should neither be impaired nor infringed upon. It therefore primarily protects, and gives priority to, the territorial preservation of States and seeks to avoid their fragmentation or disintegration due to separatist forces. However the saving clause in its latter part implies that if a State fails to comport itself in accordance with the principle of equal rights and self-determination of peoples, an exceptional situation may arise whereby the ethnically or racially distinct group denied internal selfdetermination may claim a right of external self-determination or separation from the State which could effectively put into question the State's territorial unity and sovereignty ${ }^{67}$.

Como se puede apreciar, subraya en primer lugar que debe existir una situación excepcional de negación de los derechos y libertades de un pueblo dentro de un Estado y que -en consecuencia- se podrá reclamar la autodeterminación externa, aun alterando la integridad territorial del Estado en cuestión. A su juicio, la quiebra de la integridad territorial del Estado es la respuesta excepcional del Derecho vigente ante una situación igualmente excepcional del Estado, que pierde -por su conducta contraria al Derecho- el derecho de defensa de sus fronteras, al no defender ni tratar en igualdad a todos los pueblos que constituyen su población. Recalca, asimismo, el vínculo existente entre la negación de la autodeterminación interna y el derecho de los pueblos a ejercer la autodeterminación externa mediante la secesión unilateral no-colonial.

66 Véase, entre otros, BuchHeIT, L.C., Secession: The legitimacy of self-determination, New Haven, 1978, p. 220 y ss; THÜrer, D., «Das Selbstbestimmungsrecht der Völker», Archiv des Völkerrechtes, 22, 1984, pp, 113, 127 y ss; TOMUSCHAT, Ch., «Secession and Self-determination», en Secession: international law perspective, Marcelo Kohen (ed.), Cambridge 2006, p. 33.

67 I.C.J. Reports, de 22 de julio de 2010, Opinión Consultiva sobre Kosovo, párrafos 403-412 (opinión separada del Juez Yusuf). 
Ahora bien, la mera negación de la autodeterminación interna no es suficiente para argumentar una secesión correctiva. Las personas afectadas deben ser tratadas en su misma existencia de forma discriminatoria y grave con medidas de extrema violencia ejercidas por el régimen gobernante. Solo este tipo de circunstancias excepcionales y las violaciones más graves de los derechos humanos, como el genocidio, los asesinatos en masa y la limpieza étnica... podrían justificar un supuesto «derecho especial o cualificado de secesión» que permitiría el ejercicio de la libre determinación externa a través de la secesión unilateral. Solo si, además, no existen otras vías para frenar tales violaciones o cuando se hayan agotado otras posibles soluciones negociadas y siempre y cuando una clara mayoría de la población afectada apoye por medios democráticos hacer efectivo el derecho de autodeterminación externa ${ }^{68}$. Es decir, la invocación de la autodeterminación como último recurso no es un cheque en blanco en manos de los grupos «separatista», sino que puede ejercerse solo para hacer frente a una situación de tal magnitud que afecte a obligaciones imperativas y erga omnes del orden internacional; y siempre y cuando que se hayan agotado todas las posibles vías de solución; y que se ejerza según «según un proceso debido», y no por la vía unilateral ${ }^{69}$, ya que entre, otras cuestiones, el procedimiento para la secesión, debe ser un proceso pacífico y democrático ${ }^{70}$.

Las condiciones o requisitos que legitimarían la invocación del derecho a la autodeterminación externa, como último remedio, y ante una situación concreta y de grave de violación de la autodeterminación interna quedan ya esbozados en la cláusula de salvaguarda del párrafo 7 de la Resolución 2625.

En primer lugar, como sostuvo Cassese, el derecho a la secesión unilateral solo podría ejercerse, cuando la discriminación grave contra un pueblo sea deliberada, sostenida y sistemática, con «la exclusión de cualquier posibilidad de una posible solución pacífica dentro de la estructura estatal existente $\gg^{71}$. En contrario, los casos aislados de discriminación o la aplicación involuntaria de los principios discriminatorios por parte de un gobierno contra un pueblo, no legitimarían automáticamente a ese pueblo a incoar el

68 Cfr., RaIc, D., Statehood and Self-Determination, The Hague, Kluwer Law, 2002, p. 365.

69 Véase, entre otros, Dunoff, J. L.; Ratner, S.R.; Wippman, D., International Law, Norms, Actors, Process, Aspen Publishers, 2010, p. 222.

70 Cfr., Peters, A., «Does Kosovo Lie in the Lotus-Land of Freedom?», Leiden Fournal of International Law, 24, 2011, p. 99.

71 CASSESE, A., Self-determination of peoples: a legal reappraisal, Cambridge, Cambridge University Press, 1999, pp. 119-120. 
derecho a la secesión unilateral. Se hace necesario un nivel adicional de dolus, o malicia intencional, como el flagrante desprecio por los derechos humanos fundamentales. Estos requisitos operan como una «prueba de umbral» general para la operación de los derechos del párrafo siete, asegurando que la secesión unilateral solo se permita bajo condiciones especialmente graves. Así, por ejemplo, en el caso Kosovo, la Corte llegó a la conclusión de que la adopción de la declaración unilateral de independencia no había violado ninguna regla aplicable del Derecho Internacional» ${ }^{72}$, una vez analizada los actos concretos de discriminación y las muchas vías de negociación fallidas para poner fin a aquellas violaciones ${ }^{73}$.

Una segunda condición relevante pero implícita en la cláusula de salvaguarda es que la discriminación deliberada, sostenida y sistemática debe poseer suficiente contemporaneidad. Debe existir un vínculo temporal suficiente entre la supuesta discriminación y la demanda resultante de secesión unilateral. Sin este requisito, la secesión unilateral quedaría ilimitada en el tiempo por abusos a los derechos humanos que podrían haber ocurrido cientos de años antes ${ }^{74}$. De acuerdo con el factor temporal, la población kosovar podría haber reclamado el derecho a la autodeterminación durante los actos militares del gobierno de Milosevic, pero no más tarde, ni mucho menos después de que el Consejo de Seguridad aprobase la Resolución 1244 (1999). El tiempo preciso necesario para la expiración de un derecho a la secesión unilateral es obviamente discutible, aunque algún sector doctrinal ha llegado a afirmar que se requiere un plazo mínimo de diez a quince años desde el cese de los abusos ${ }^{75}$. Ciertamente, un

72 I.C. J. Reports, 2010, párrafo 122

73 Ibid, párrafos 64-79

74 ANDERSON, G., «Unilateral non-colonial secession in International Law and Declaratory General Assembly Resolutions: textual content and legal effects», Denver fournal of International Law and Policy, vol. 41, 2012-2013, p. 359. GoodWIN, M., «Special Issue Introduction - What Future for Kosovo? - From Province to Protectorate to State? Speculation on the Impact of Kosovo's Genesis upon the Doctrines of International Law», German Law Fournal, vol. 8, 2007, pp. 1-20, available at http://www.germanlawjournal.com/index.php? pageID=11\&artID=786, quien ha subrayado que « $[\mathrm{t}]$ he integration of Mercia into the emerging English nation at the point of the sword of the King of Wessex was probably no laughing matter, even by 10th century standards; could it be used as a basis for a claim to secede from its southern neighbors?»

75 Goodwin, M., «Special Issue Introduction - What Future for Kosovo? - From Province to Protectorate to State? Speculation on the Impact of Kosovo's Genesis upon the Doctrines of International Law», German Law fournal, vol. 8, 2007, pp 6-7., en estas páginas reflexiona sobre el tiempo necesario que debería transcurrir para la expiración de un derecho de autodeterminación, que justificase una secesión no colonial unilateral, pero no llega a proponer una a respuesta concreta. 
período de tiempo corto, como cinco años, no debe poner en peligro una reclamación válida.

Un tercer requisito implícito, pero particular de la citada cláusula de salvaguarda es que cualquier Estado nuevo, que nazca de una declaración unilateral de independencia debe garantizar que los derechos humanos, de todos los pueblos y también minorías que estén bajo su soberanía deben quedar protegidos por medio de instituciones constitucionales ${ }^{76}$. Esta condición, que por conveniencia podría denominarse «principio de coherencia interna», garantizaría que la norma internacional que no prohíbe taxativamente una secesión unilateral, como último remedio frente a graves violaciones de derechos humanos, no pueda bajo ninguna circunstancia, utilizarse para fomentar o perpetuar violaciones de derechos humanos. Este principio de coherencia interna también puede considerarse que informa las Directrices de la entonces Comunidad Europea sobre el Reconocimiento de Nuevos Estados, promulgadas a fines de 1991 en respuesta a acontecimientos políticos en Europa ${ }^{77}$. Esas Directrices establecían que los Estados miembros de la Comunidad Europea «adoptarán una posición común sobre el proceso de reconocimiento de... los nuevos Estados, que requiere», entre otras cosas, «garantías para los derechos de los grupos étnicos y nacionales y las minorías de conformidad con el compromisos suscritos en el marco de la CSCE».

$\mathrm{Y}$, finalmente, cualquier declaración unilateral de independencia realizada de conformidad con lo establecido en la cláusula de salvaguarda de la Resolución 2625 de la AG exigiría igualmente al nuevo Estado así creado que cumpla con las exigencias jurídicas inherentes a la estatalidad, tal y como se contemplan en la Convención de Montevideo de 1933. Una entidad podría alcanzar la condición de Estado si cumple con los siguientes criterios: si tiene un territorio definido, una población permanente, un gobierno efectivo sobre dicho territorio y sobre toda esa población y siempre y cuando tenga capacidad de entrar en relaciones internacionales y de imponer independencia política ${ }^{78}$.

76 Cfr., Turk, D., «Recognition of States: a Comment», European fournal of International Law, 1993 , p. 72.

77 Véase, la Declaración de los Doce sobre las líneas directrices referidas al reconocimiento de nuevos Estados en Europa del Este y Unión Soviética, acordada en la reunión ministerial extraordinaria de la CPE de 16-12-91, REDI, 1992-1, p. 119; también puede consultarse en el Bol. CE 1991-12, punto 1.4.5, p. . 120.

78 Cfr. art. 1 de la Convención de Montevideo sobre los derechos y las obligaocnes d elos Estdos 1 of the Montevideo Convention on the Rights and Duties of States, 26 Dec. 1933, 156 LNTS 19. La estadidad es una teoría legal que busca justificar la atribución de la estadidad a criterios 
Todos estos requisitos confirman que la declaración de independencia unilateral de cualquier futuro nuevo Estado puede ser válidamente solo bajo condiciones muy estrictas. Solo así se permitiría la secesión unilateral en caso de discriminación deliberada, sostenida y sistemática de un pueblo, a pesar de formar parte de la integridad territorial de un Estado. En otras palabras, las declaraciones unilaterales de independencia solo pueden aceptarse en el derecho internacional, cuando las violaciones de los derechos humanos son particularmente extremas, como sucedió, por ejemplo, en Kosovo antes de la intervención de la OTAN en 1999, pero no en febrero de $2008^{79}$.

\section{REFLEXIONES FINALES: ¿ES POSIBLE LA REIVINDICACIÓN DE indePendencia de Cataluña de aCUerdo con el Derecho INTERNACIONAL SOBRE LA AUTODETERMINACIÓN?}

Habida cuenta de las explicaciones doctrinales del derecho a la autodeterminación de los pueblos, según el estado actual del Derecho internacional, resulta relativamente fácil responde si las actuales reivindicaciones de independencia de Cataluña pueden ampararse lícitamente en el orden internacional.

La cuestión elemental a dilucidar es si las condiciones exigidas en la cláusula de salvaguarda de la Resolución 2625 se cumplen en Cataluña para que el «pueblo catalán» pueda ejercer la autodeterminación externa y declare la tan anhelada, solo por algunos, que no por una aplastante mayoría de los españoles, la República de Cataluña. La situación jurídica es nítida desde el derecho internacional. En mi opinión, es extremadamente difícil interpretar y demostrar una plausible legitimación para una lícita separación unilateral de Cataluña de España, a la luz de las consideraciones generales de autodeterminación ni como «secesión correctiva», ni como último remedio ni mucho menos humanitaria.

\footnotetext{
objetivos, que al menos en teoría son independientes de la realidad política que subyace en muchos intentos de secesión o separación. De hecho, el artículo 3 de la Convención de Montevideo establece que «[1] a existencia política del estado es independiente del reconocimiento de los otros estados».Statehood is a legal theory that seeks to justify the attribution of statehood on objective criteria, which are at least in theory independent from the political reality underlying many attempts at secession or separation. In fact, article 3 of the Montevideo Convention states that « $[\mathrm{t}]$ he political existence of the state is independent of recognition by the other states.»

79 Oeter S., «Secession, territorial Integrity and the Security Council», en Kosovo and International Law, Peter Hilpold (ed.), p. 119.
} 
Cataluña no es un pueblo colonial, ni un territorio no autónomo. Tampoco es el Kosovo de Milosevic. Cataluña es una de las 17 comunidades autónomas que conforman el Reino de España, y como tal es una entidad territorial administrativa española dentro del derecho constitucional nacional, tal y como lo promulga la Constitución Española de 1978. Al igual que otras comunidades autónomas, Cataluña está dotada de una cierta autonomía legislativa; tiene sus propios representantes en el Senado de las Cortes Españolas; y ha adquirido los poderes ejecutivos y administrativos previsto en su Estatuto de Autonomía.

El primer Estatuto de Autonomía fue adoptado en 1932 durante la Segunda República de España (1931-1939). Después de la Guerra Civil Española (1936-1939) se suspendió el Estatuto de Cataluña y, en consecuencia, se prohibió el catalán (su lengua cultural). A modo casi de anécdota podría decirse que, en todo caso, Cataluña hubiera podido amparase en ese supuesto derecho a separarse por discriminación cuando durante el franquismo se prohibió el uso de la lengua catalana, pero no ahora pasadas casi más de cinco décadas y cuando esa hipotética discriminación lingüística-cultural ha sido más que superada con la nueva España constitucional de 1978. Con la transición democrática y la entrada en vigor de la Constitución española (1978), todos los estatutos de autonomía fueron restaurados para todas las entidades territoriales, incluida Cataluña.

Bajo el título, «Unidad nacional y devolución a nacionalidades y regiones», el artículo 2 de la Constitución Española establece que:

La Constitución se fundamenta en la indisoluble unidad de la Nación española, patria común e indivisible de todos los españoles, y reconoce y garantiza el derecho a la autonomía de las nacionalidades y regiones que la integran y la solidaridad entre todas ellas.

En otras palabras, la Constitución española reconoce y garantiza la unidad y el derecho a la autonomía, entendidos como el derecho de cada autoridad local a acceder al autogobierno ${ }^{80}$. Esta norma implica el reconocimiento de la diversidad del estatus legal público de cada una de las autoridades loca$\operatorname{les}^{81}$, así como el reconocimiento del deber de lealtad en el ejercicio de poderes que son específicos de cada autoridad local ${ }^{82}$.

80 STC 100/1984, RTC 1984, 100 F.2

81 STC76/1983, RTC 1983, 76, F.2.

82 STC 46/1990, RTC 1990, 46, F.4 
Por regla general, casi ningún Estado reconoce en la actualidad en sus normas constitucionales o fundamentales a sus distintos componentes o comunidades humanas existentes dentro del Estado el derecho a separarse unilateralmente. Tan sólo existe alguna excepción en aquellos Estados que se definen a sí mismos como constituido por una pluralidad de pueblos que tienen el derecho a la libre determinación y, por lo tanto, a la separación. Sin duda, el incumplimiento de estas normas nacionales relevantes por parte del gobierno central puede abrir el camino para una secesión legal desde el punto de vista del derecho internacional, tal y como era el caso de la República Federativa Socialista de Yugoslavia con respecto a sus repúblicas constituyentes. En la actualidad, este tipo de disposiciones constitucionales existen en Etiopía, San Cristóbal y Nieves y Uzbekistán, pero no en España. Como ya se ha visto, la Constitución española reconoce y garantiza el derecho a la autonomía, entendido como el derecho de cada autoridad local a acceder al autogobierno (art. 143 de la Constitución Española). En 1979, un nuevo Estatuto de autonomía entró en vigor para Cataluña y se reformó en julio de 2006. Según este Estatuto de Autonomía, Cataluña tiene su propio gobierno, un Tribunal Supremo y una defensa territorial separada con competencias y poderes locales. Como en muchos otros sistemas jurídicos, el gobierno catalán solo puede actuar dentro de las áreas limitadas en las que ha recibido el poder del gobierno central de España a través del Estatuto de Autonomía. El Estatuto de Autonomía de Cataluña es el marco legal para el acuerdo de autogobierno entre el Estado español y Cataluña, el Gobierno catalán asume amplios poderes y gestiona diversos campos como la educación, los asuntos sociales, el tránsito, la determinación de las políticas económicas y el comercio, etc. ${ }^{83}$ Es competente también para la construcción de instalaciones públicas como hospitales, escuelas primarias y secundarias, universidades, hogares para ancianos, así como ciertas acciones en política exterior, entre otras. En resumen, durante más de treinta años, España ha sido una democracia en la que Cataluña goza de una autonomía sustancial con jurisdicción doméstica en el campo de la salud, la educación, los impuestos locales... Al mismo tiempo, el gobierno regional catalán está representado en el parlamento nacional y el pueblo catalán no está sometido a ningún tipo de s a discriminación racial, lingüística o cultural en comparación con las poblaciones de otras regiones españolas, comunidades autónomas, como Navarra o el País Vasco. Por todas estas razones, está claro

83 Title IV Competences (arts. 110-173), the Catalan Statute of Autonomy of 2006. 
que Cataluña no es Kosovo y su situación jurídica respecto al derecho a la autodeterminación interna, según el orden internacional bastante clara. No se dan en Cataluña las condiciones necesarias mínimas internas que pudieran legitimar al gobierno catalán a invoca su autodeterminación externa, como consecuencia de una fallida autodeterminación interna.

Por eso, en los últimos años, sus presidentes locales -desde Mas hasta Torra- han cambiado su demagogia política, y ahora apelan a un nuevo derecho humano: el llamado «derecho a decidir», ya que los objetivos separatistas del gobierno regional de Cataluña no pueden fundamentase en el derecho internacional sobre autodeterminación, tal y como se entiende y aplica en la actualidad. Sin embargo, nada obsta a que Cataluña intente negociar nuevos campos de autonomía en virtud del derecho público español como una manifestación más del derecho interno de autodeterminación.

Finalmente, hay que decir que más allá de la cuestión legal de la validez de una declaración unilateral de independencia de Cataluña en virtud del derecho internacional vigente, la cuestión catalana implica otras muchas otras cuestiones prácticas. De hecho, ¿qué pasaría si Cataluña declarase (de nuevo) la independencia unilateral sin el consentimiento del Gobierno español y sin suspenderla acto seguido? ¿Podrían terceros Estados reconocer de facto en un futuro a la hipotética República de Cataluña a pesar de la contravención de las normas internacionales sobre la materia? 
OTROS ESTUDIOS DOCTRINALES 
